\title{
Decreased expression of microRNA-124 is an independent unfavorable prognostic factor for patients with breast cancer
}

\author{
Liang-liang Dong ${ }^{\dagger}$, Li-ming Chen $^{\dagger}$, Wei-min Wang and Liang-ming Zhang ${ }^{*}$
}

\begin{abstract}
Background: MicroRNA-124 (miR-124) has been reported to be downregulated in breast cancer. However, its clinical significance and prognostic value in breast cancer have not been extensively studied.

Methods: The tissue expression levels of miR-124 were measured using quantitative real-time PCR in 133 breast cancer patients. The correlation between the miR-124 levels and the clinicopathological factors of the patients was also analyzed. Survival and Cox proportional-hazards regression analyses were performed to determine the correlation between miR-124 expression levels and prognosis in the patients.
\end{abstract}

Results: Quantitative real-time PCR analysis showed that miR-124 had lower expression in breast cancer specimens than that in matched adjacent normal breast tissues ( $0.39 \pm 0.16$ vs. $1.00 \pm 0.39 ; P<0.05)$. Low miR-124 expression level was significantly associated with advanced TNM stage $(P=0.011)$, lymph node metastasis $(P=0.012)$, and poorer pathological differentiation ( $P=0.023$ ). A significant difference was found that breast cancer patients with low miR-124 expression level had distinctly shorter overall survival than patients with high miR-124 expression level (63.8\% vs. 35.2\%, $P=0.03)$. Furthermore, multivariate analysis of the prognosis factors with a Cox proportional hazards model confirmed that low miR-124 expression was a significant independent predictor of poor survival in breast cancer $(H R=3.16,95 \%$ Cl: $1.79-9.13, P=0.017)$.

Conclusion: These findings proved that the decreased expression of miR-124 might be associated with tumor progression and poor prognosis in patients with breast cancer.

Virtual Slides: The virtual slide(s) for this article can be found here: http://www.diagnosticpathology.diagnomx.eu/vs/ 3752603721493544

Keywords: MicroRNA, MicroRNA-124, Breast cancer, Prognosis, Biomarker

\section{Background}

Breast cancer ranks as the most common cancer and the first major cause of cancer death among women in the world, with an expected 1,383,500 newly diagnosed cases and 458,400 deaths in 2010 [1]. It is necessary to further explore the molecular mechanisms of breast cancer in order to improve the therapeutic effect. MicroRNAs (miRNAs) are short ( 19-23 nucleotides), non-coding RNA molecules that are recognized as endogenous physiological regulators of gene expression. These small

\footnotetext{
*Correspondence: yt_zhangliangming@126.com

${ }^{\dagger}$ Equal contributors

Department of Medical Oncology, Yantai Yuhuangding Hospital, 20 Yuhuangding East Road, Yantai, Shandong 264000, China
}

RNAs are capable of controlling gene expression either by repressing translation and transcription [2], or by activating transcription [3]. Dysregulation of miRNA expression has been found in various types of human cancers, including breast cancer, colon cancer, and lung cancer, chronic lymphocytic leukemia and malignant glioma [4-8]. MiRNA expression profiles that are able to further distinguish between normal breast tissue and breast cancer have been presented by several groups $[7,9]$. These differences in expression for certain miRNAs in breast cancer suggest that miRNAs can be useful biomarkers for breast cancer progression and clinical course or may even be key molecular events in the transformation process. 
MicroRNA-124 (miR-124), a brain-enriched miRNA, was first found to be involved in stem cell regulation and neuro-development [10,11]. Previous research confirmed that miR-124 was epigenetically silenced in various types of cancers [12-16]. The study by $\mathrm{Li}$ et al showed that miR-124 was downregulated in breast cancer, and miR-124 might be a tumor suppressor in breast cancer via the regulation of flotillin-1(FLOT1) [17]. In the present study, we aimed to investigate the clinical significance and prognostic value of miR-124 in breast cancer.

\section{Methods}

\section{Ethics statement, patients and tissue specimens}

The use of tissues for this study has been approved by the Ethics Committee of Yantai Yuhuangding Hospital. At the time of initial diagnosis, all patients had provided consent in the sense that their tumor samples could be used for investigational purposes. Written informed consents were received from all participants involved in the study. Breast cancer tissues and adjacent normal tissues were obtained from 133 patients. All patients underwent breast surgical resection at the Surgery Department, Yantai Yuhuangding Hospital from April 2006 to March 2012. The carcinomas and the adjacent normal tissues were snap-frozen in liquid nitrogen $(\mathrm{N} 2)$ and stored at $-80^{\circ} \mathrm{C}$ until use. All the specimens were diagnosed by two pathologists separately to determine the pathological classification of breast cancer. None of the patients recruited in this study had undergone preoperative chemotherapy or radiotherapy. The clinical features of the patients, including age, tumor size, histologic grade, lymph node status, and histology, were shown in Table 1.

\section{Reverse transcription and quantitative real-time PCR}

Total RNA and enrichment of small RNA from fresh samples was isolated using the mirVana miRNA Isolation kit (Ambion, Austin, TX, USA) according to the manufacturer's instructions, and then stored at $-70^{\circ} \mathrm{C}$ until use. Total RNA from fresh cultured cells was carried out with TRIzol reagent (Invitrogen, Karlsruhe, Germany) following the manufacturer's protocol. Realtime RT-PCR method was used to assess the expression levels of miR-124 with Express SYBR ${ }^{\circ}$ GreenER qPCRs supermix Universal kit (Invitrogen) on a Rotor-gene 6000 system (Qiagen, Valencia, CA, USA). U6 RNA was used as an endogenous reference for normalizing the expression levels of miR-124. Initially, we calculated a ${ }^{\Delta} \mathrm{Ct}$ (target-reference), which is equal to the difference between threshold cycles for miR-124 (target) and those for U6 RNA (reference). The fold-change between cancer tissues and normal breast tissue control for miR-124 was calculated with the $2^{\Delta \Delta} \mathrm{Ct}$ method, in which ${ }^{\Delta \Delta} \mathrm{Ct}={ }^{\Delta} \mathrm{Ct}$ (target-reference in tumor samples) $-{ }^{\Delta} \mathrm{Ct}$ (target-reference
Table 1 Correlation between miR-124 expression and characteristics of breast cancer patients

\begin{tabular}{|c|c|c|c|c|}
\hline \multirow[t]{2}{*}{$\begin{array}{l}\text { Clinicopathological } \\
\text { factors }\end{array}$} & \multirow[t]{2}{*}{$\begin{array}{l}\text { Cases } \\
\text { number }\end{array}$} & \multicolumn{2}{|c|}{$\begin{array}{l}\text { miR-124 } \\
\text { expression level }\end{array}$} & \multirow[t]{2}{*}{$P$ value } \\
\hline & & $\begin{array}{l}\text { Low } \\
(n=66)\end{array}$ & $\begin{array}{l}\text { High } \\
(n=67)\end{array}$ & \\
\hline \multicolumn{5}{|l|}{ Age } \\
\hline$<50$ years & 56 & 21 & 35 & 0.19 \\
\hline$\geq 50$ years & 77 & 45 & 32 & \\
\hline \multicolumn{5}{|l|}{ Tumor size } \\
\hline$<2.5 \mathrm{~cm}$ & 70 & 27 & 43 & 0.13 \\
\hline$\geq 2.5 \mathrm{~cm}$ & 63 & 39 & 24 & \\
\hline \multicolumn{5}{|l|}{ Lymph node metastasis } \\
\hline Yes & 59 & 41 & 18 & $0.012^{*}$ \\
\hline No & 74 & 25 & 49 & \\
\hline \multicolumn{5}{|l|}{ TNM stage } \\
\hline$|/| \mid$ & 92 & 35 & 57 & $0.011^{*}$ \\
\hline III & 41 & 31 & 10 & \\
\hline \multicolumn{5}{|c|}{ Pathological differentiation } \\
\hline $\begin{array}{l}\text { Moderately and highly } \\
\text { differentiated }\end{array}$ & 100 & 45 & 55 & $0.023^{*}$ \\
\hline Poorly differentiated & 33 & 21 & 12 & \\
\hline \multicolumn{5}{|l|}{ ER } \\
\hline Positive & 67 & 27 & 40 & 0.31 \\
\hline Negative & 66 & 39 & 27 & \\
\hline \multicolumn{5}{|l|}{ PR } \\
\hline Positive & 59 & 25 & 34 & 0.15 \\
\hline Negative & 74 & 41 & 33 & \\
\hline \multicolumn{5}{|l|}{ HER2 status } \\
\hline Over expressed & 65 & 29 & 36 & 0.08 \\
\hline Negative & 68 & 37 & 31 & \\
\hline
\end{tabular}

* $P<0.05$ was considered significant.

in normal samples). The relative expression levels of miRNAs in cancer compared to their non-tumorous controls were calculated using the method of $2^{-\Delta \Delta} \mathrm{Ct}$. The quantitative real-time PCR primers for miR-124 were designed as follows: forward: 5'-GATACTCATAAGGCACG CGG-3' and reverse: 5' -GTGCAGGGTCCGAGGT-3'.

\section{Statistical analysis}

All statistical analyses were performed using the SPSS 18.0 statistical software package (SPSS Inc., Chicago, IL, USA). The Student's t-test was used to analyze the differences in miR-124 expression between the tumor and normal tissues. Relationships between miR-124 expression level and the clinicopathological characteristics were studied using the chi-square test and Fisher's exact test or independent $t$ test. Survival curves were plotted by the Kaplan-Meier method and compared by the 
log-rank test. The survival data were evaluated by univariate and multivariate Cox regression analyses. $\mathrm{P}<0.05$ was considered statistically significant.

\section{Results}

The expression of miR-124 in breast cancer tissues and adjacent normal tissues analyzed by quantitative real-time PCR

Quantitative real-time PCR analysis showed that miR124 had lower expression in breast cancer specimens than that in matched adjacent normal breast tissues $(0.39 \pm 0.16$ vs. $1.00 \pm 0.39 ; \mathrm{P}<0.05$, shown in Figure 1$)$. The median miR-124 expression level of all breast cancer cases was 0.38 , which was utilized to divide breast cancer patients into two groups. 66 cases were assigned to the low-expression group, the remaining 67 cases were assigned to the high-expression group.

The relationship between miR-124 expression level and clinicopathological characteristics

The relationship between miR-124 expression level and clinicopathological characteristics was shown in Table 1. Low miR-124 expression level was significantly associated with advanced TNM stage $(\mathrm{P}=0.011)$, lymph node metastasis $(\mathrm{P}=0.012)$, and poorer pathological differentiation $(\mathrm{P}=0.023)$. However, there was no significant association between miR-124 expression and other clinicopathological factors, including age $(\mathrm{P}=0.19)$, and tumor size $(\mathrm{P}=0.13)$, ER status $(\mathrm{P}=0.31), \mathrm{PR}$ status $(\mathrm{P}=0.15)$, and HER2 sta$\operatorname{tus}(\mathrm{P}=0.08)$.

\section{Impact of miR-124 expression on prognosis of breast cancer}

Kaplan-Meier method and log-rank test were used to evaluate the differences of overall survival between lowexpression group and high-expression group. A significant difference was found that breast cancer patients with low

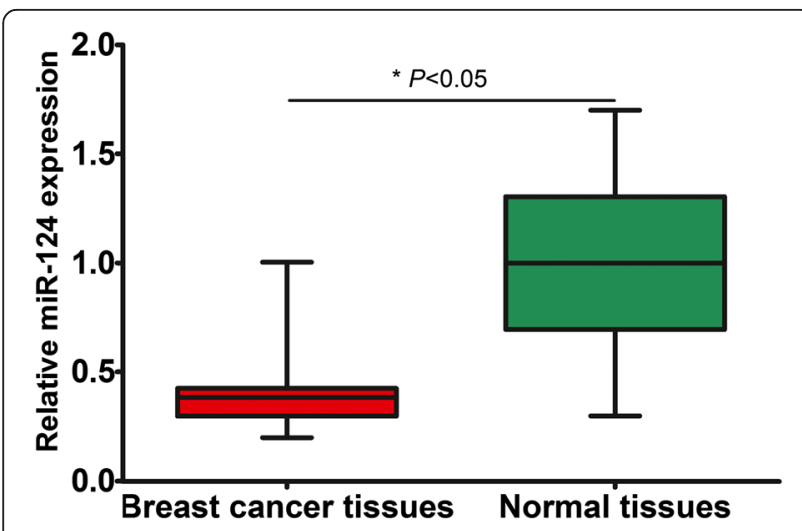

Figure 1 The expression of miR-124 was determined by quantitative real-time PCR in 133 paired human breast cancer and adjacent normal tissues.
miR-124 expression level had distinctly shorter overall survival than patients with high miR-124 expression level (63.8\% vs. $35.2 \%, \mathrm{P}=0.03$, shown in Figure 2 ). Univariate and multivariate analyses were utilized to evaluate whether the miR-124 expression level and various clinicopathological features were independent prognostic parameters of breast cancer patient outcomes. The results of analysis are shown in Table 2. A multivariate analysis of the prognosis factors with a Cox proportional hazards model confirmed that low miR-124 expression was a significant independent predictor of poor survival in breast cancer $(\mathrm{HR}=3.16$, 95\% CI: 1.79-9.13, P = 0.017).

\section{Discussion}

Breast cancer is the most common malignancy in women and is a leading cause of cancer-related deaths among women worldwide. Despite tremendous efforts in developing multimodal treatments, the clinical outcome of breast cancer patients remains unfavorable. The survival time varies considerably between patients. Heterogeneity in both cytology and gene expression makes it difficult to coordinate effective therapeutic strategies which work for every patient. Thus, it is of great significance to realize the underlining molecular mechanisms and to identify powerful prognostic indicator for breast cancer.

The tumor-related miRNAs function as tumor suppressors or oncogenes and modulate

many aspects of carcinogenesis, including cell proliferation, cell-cycle control, metastasis, as well as angiogenesis [18-20]. Recently, the correlations of dysregulated

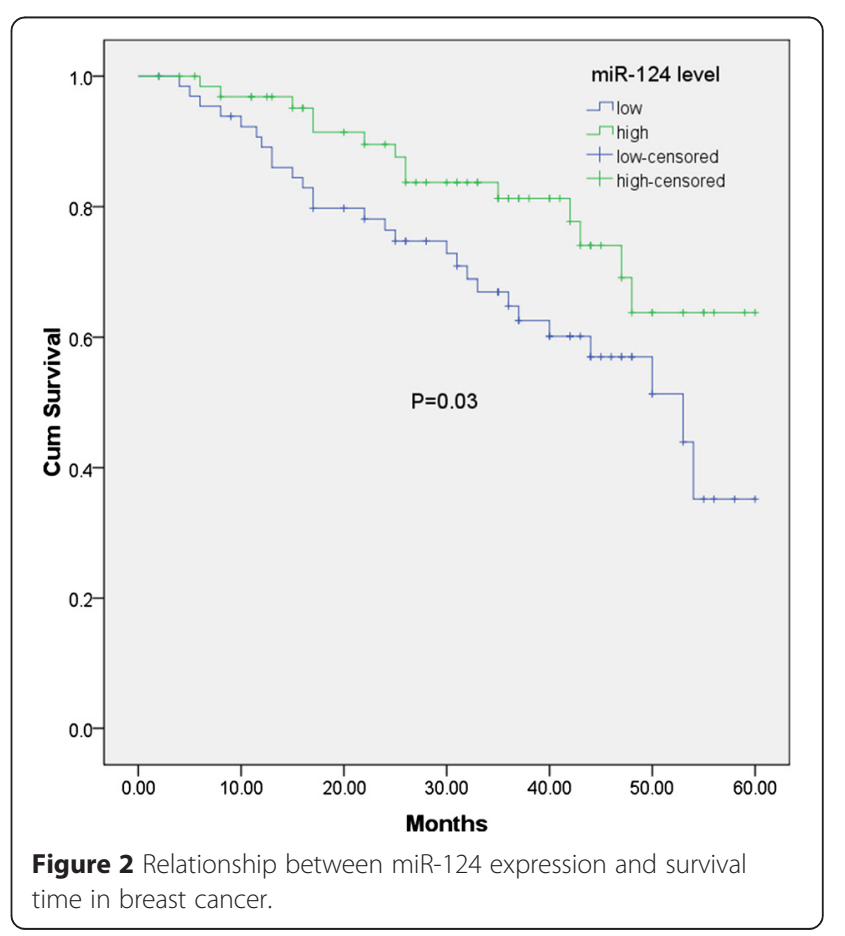


Table 2 Univariate and multivariate analyses of different prognostic parameters on breast cancer survival

\begin{tabular}{|c|c|c|c|c|c|c|}
\hline \multirow[b]{2}{*}{ Variables } & \multicolumn{3}{|c|}{ Univariate analyses } & \multicolumn{3}{|c|}{ Multivariate analyses } \\
\hline & $\mathrm{HR}$ & $95 \% \mathrm{Cl}$ & $P$ & $\mathrm{HR}$ & $95 \% \mathrm{Cl}$ & $\mathbf{P}$ \\
\hline Age & 1.45 & $0.88-4.17$ & 0.32 & 1.22 & $0.78-3.44$ & 0.52 \\
\hline Tumor size & 1.67 & $0.78-5.18$ & 0.11 & 1.39 & $0.81-4.22$ & 0.18 \\
\hline Lymph node metastasis & 3.88 & $1.87-11.27$ & 0.018 & 3.36 & $1.46-10.11$ & 0.029 \\
\hline TNM stage & 4.01 & $1.83-12.18$ & 0.012 & 3.48 & $1.59-9.83$ & 0.019 \\
\hline Pathological differentiation & 3.32 & $1.65-9.82$ & 0.005 & 2.81 & $1.56-8.87$ & 0.006 \\
\hline ER status & 0.67 & $0.42-3.25$ & 0.31 & 0.72 & $0.18-2.03$ & 0.35 \\
\hline PR status & 1.52 & $0.67-3.18$ & 0.27 & 1.27 & $0.39-2.88$ & 0.41 \\
\hline HER2 status & 1.66 & $0.25-2.98$ & 0.25 & 1.91 & $0.27-3.75$ & 0.22 \\
\hline miR-124 level & 2.28 & $1.28-7.11$ & 0.023 & 3.16 & $1.79-9.13$ & 0.017 \\
\hline
\end{tabular}

*P $<0.05$ was considered significant.

miRNAs with human breast cancer are increasingly reported, and these data indicate that specific miRNA expression patterns are associated with the biological and clinical properties of breast cancer. However, there have been a limited number of studies on the potential of miRNAs used for prognostic biomarkers and therapeutic molecular targets in breast cancer [21,22].

Previous research confirmed that miR-124 was epigenetically silenced in various types of cancers [12-16]. The expression level and mechanism of miR-124 have also been investigated in breast cancer. Han et al found that miR-124 played a critical role in inhibiting the invasive and metastatic potential of breast cancer cells, probably by directly targeting the CD151 genes. Their findings highlighted an important role of miR-124 in the regulation of invasion and metastasis of breast cancer cells and suggested a potential application for miR-124 in breast cancer treatment [12]. In the study by Li et al, luciferase reporter assay and western blot were used to verify E26 transformation specific-1 (Ets-1) as a potential major target gene of miR-124, and the results showed that miR-124 could bind to putative binding sites within the Ets-1 mRNA 3' untranslated region (UTR) to reduce its expression. Based on these findings, they proposed that miR-124 and Ets-1 might serve as a therapeutic agent in breast cancer [23]. In another study, Li et al showed that miR-124 was downregulated in breast cancer, and miR-124 might be a tumor suppressor in breast cancer via the regulation of FLOT1 [17]. In the present study, we aimed to investigated the clinical significance of miR-124 in breast cancer. Quantitative real-time PCR analysis showed that miR-124 had lower expression in breast cancer specimens than that in matched adjacent normal breast tissues. Low miR-124 expression level was significantly associated with advanced TNM stage, lymph node metastasis, and poorer pathological differentiation. Kaplan-Meier method and log-rank test were used to evaluate the differences of overall survival between low-expression group and high-expression group. A significant difference was found that breast cancer patients with low miR-124 expression level had distinctly shorter overall survival than patients with high miR-124 expression level. Furthermore, multivariate analysis of the prognosis factors with a Cox proportional hazards model confirmed that low miR-124 expression was a significant independent predictor of poor survival in breast cancer.

\section{Conclusions}

In conclusion, these findings proved that the decreased expression of miR-124 was associated with tumor progression and poor prognosis in patients with breast cancer, suggesting miR-124 might be a novel and valuable signature for predicting the clinical outcome of patients with breast cancer.

\section{Competing interests}

The authors declare that they have no competing interests.

\section{Authors' contributions}

LLD and LMZ designed the study, carried out the experiments and drafted the manuscript; LMC, WMZ, and CYW participated in the experiments and data analysis. All authors read and approved the final manuscript.

Received: 11 November 2014 Accepted: 25 March 2015

Published online: 29 April 2015

\section{References}

1. Siegel R, Ward E, Brawley O, Jemal A. Cancer statistics, 2011: the impact of eliminating socioeconomic and racial disparities on premature cancer deaths. CA Cancer J Clin. 2011;61(4):212-36.

2. Bartel DP. MicroRNAs: target recognition and regulatory functions. Cell. 2009;136(2):215-33.

3. Li LC. The multifaceted small RNAs. RNA Biol. 2008;5(2):61-4.

4. Schetter AJ, Leung SY, Sohn JJ, Zanetti KA, Bowman ED, Yanaihara N, et al. MicroRNA expression profiles associated with prognosis and therapeutic outcome in colon adenocarcinoma. Jama. 2008;299(4):425-36.

5. Yu SL, Chen HY, Chang GC, Chen CY, Chen HW, Singh S, et al. MicroRNA signature predicts survival and relapse in lung cancer. Cancer Cell. 2008;13(1):48-57.

6. Fulci V, Chiaretti S, Goldoni M, Azzalin G, Carucci N, Tavolaro S, et al. Quantitative technologies establish a novel microRNA profile of chronic lymphocytic leukemia. Blood. 2007;109(11):4944-51. 
7. Iorio MV, Ferracin M, Liu CG, Veronese A, Spizzo R, Sabbioni S, et al. MicroRNA gene expression deregulation in human breast cancer. Cancer Res. 2005;65(16):7065-70

8. Ciafre SA, Galardi S, Mangiola A, Ferracin M, Liu CG, Sabatino G, et al. Extensive modulation of a set of microRNAs in primary glioblastoma. Biochem Biophys Res Commun. 2005;334(4):1351-8.

9. Blenkiron C, Goldstein LD, Thorne NP, Spiteri I, Chin SF, Dunning MJ, et al. MicroRNA expression profiling of human breast cancer identifies new markers of tumor subtype. Genome Biol. 2007;8(10):R214.

10. Lee MR, Kim JS. Kim KS: miR-124a is important for migratory cell fate transition during gastrulation of human embryonic stem cells. Stem Cells. 2010;28(9):1550-9.

11. Cheng LC, Pastrana E, Tavazoie M, Doetsch F. miR-124 regulates adult neurogenesis in the subventricular zone stem cell niche. Nat Neurosci. 2009;12(4):399-408.

12. Han ZB, Yang Z, Chi Y, Zhang L, Wang Y, Ji Y, et al. MicroRNA-124 suppresses breast cancer cell growth and motility by targeting CD151. Cell Physiol Biochem. 2013;31(6):823-32.

13. Wang P, Chen L, Zhang J, Chen H, Fan J, Wang K, et al. Methylation-mediated silencing of the miR-124 genes facilitates pancreatic cancer progression and metastasis by targeting Rac1. Oncogene. 2014;33(4):514-24.

14. Shi XB, Xue L, Ma AH, Tepper CG, Gandour-Edwards R, Kung HJ, et al. Tumor suppressive miR-124 targets androgen receptor and inhibits proliferation of prostate cancer cells. Oncogene. 2013;32(35):4130-8.

15. Xia J, Wu Z, Yu C, He W, Zheng H, He Y, et al. miR-124 inhibits cell proliferation in gastric cancer through down-regulation of SPHK1. J Pathol. 2012;227(4):470-80.

16. Zheng F, Liao YJ, Cai MY, Liu YH, Liu TH, Chen SP, et al. The putative tumour suppressor microRNA-124 modulates hepatocellular carcinoma cell aggressiveness by repressing ROCK2 and EZH2. Gut. 2012;61(2):278-89.

17. Li L, Luo J, Wang B, Wang D, Xie X, Yuan L, et al. Microrna-124 targets flotillin-1 to regulate proliferation and migration in breast cancer. Mol Cancer. 2013;12:163.

18. Profumo V, Gandellini P. MicroRNAs: cobblestones on the road to cancer metastasis. Crit Rev Oncog. 2013;18(4):341-55.

19. Landskroner-Eiger S, Moneke I, Sessa WC. miRNAs as modulators of angiogenesis. Cold Spring Harb Perspect Med. 2013;3(2):a006643.

20. Carleton M, Cleary MA, Linsley PS. MicroRNAs and cell cycle regulation. Cell Cycle. 2007;6(17):2127-32.

21. Wang S, Li H, Wang J, Wang D. Expression of microRNA-497 and its prognostic significance in human breast cancer. Diagn Pathol. 2013;8:172.

22. Svoboda M, Sana J, Redova M, Navratil J, Palacova M, Fabian P, et al. MiR-34b is associated with clinical outcome in triple-negative breast cancer patients. Diagn Pathol. 2012;7:31.

23. Li W, Zang W, Liu P, Wang Y, Du Y, Chen X, et al. MicroRNA-124 inhibits cellular proliferation and invasion by targeting Ets-1 in breast cancer. Tumour Biol. 2014;35(11):10897-904.

\section{Submit your next manuscript to BioMed Central and take full advantage of:}

- Convenient online submission

- Thorough peer review

- No space constraints or color figure charges

- Immediate publication on acceptance

- Inclusion in PubMed, CAS, Scopus and Google Scholar

- Research which is freely available for redistribution 